\title{
Advancement of Evidence-Based Programs for Young Children with Social and Emotional Learning Difficulties
}

\author{
Mary Louise Hemmeter ${ }^{1}$ Maureen A. Conroy ${ }^{2}$
}

Published online: 1 June 2018

(c) Springer Science+Business Media, LLC, part of Springer Nature 2018

Over the past decade, there has been an increased focus on the provision of high-quality early care and education programs. This focus is in large part due to the expansion of funding for early care and education programs at the state and federal levels to ensure children and families have greater access and higher quality care and learning experiences. While much of the current focus is on early academic skills, the importance of addressing children's social-emotional development has also garnered attention. Shonkoff and Phillips (2000) have identified three critical areas of development for young children: (1) learning to regulate one's own emotions, behaviors, and attention; (2) learning language, reasoning, and problem solving; and (3) learning how to get along with others and form friendships, including resolving conflicts. Although this report was not intended to address social-emotional development specifically, it is important to note the primacy of social-emotional development in their findings.

There is a significant amount of evidence that young children who have aggressive and anti-social behaviors are likely to continue on a trajectory that includes challenging behavior, school problems, and challenges that affect social opportunities, mental health, and well-being (Brennan, Shaw, Dishion, \& Wilson, 2012; Dodge et al., 2014; Jones, Greenberg, \& Crowley, 2015). There is evidence that this trajectory starts young. Data indicate that social and emotional delays and challenges occur in $10-20 \%$ of children between the ages of 2 and 5 (Brauner \& Stephens, 2006; Egger \& Angold, 2006). In 2005, Gilliam reported that preschool-aged children were three times more likely to be expelled than children in K-12. More recent data from the Office of Civil Rights confirm these findings and highlight the extent to which children of color are disproportionately

\footnotetext{
$\triangle$ Maureen A. Conroy

mconroy@coe.ufl.edu

Vanderbilt University, Nashville, USA

2 University of Florida, Gainesville, USA
}

suspended and expelled. When children are expelled from Pre-K settings, they are removed from the settings in which they are likely to learn the social-emotional skills that will help them be successful in school and life.

For these reasons, there is growing national concern about the need to promote young children's social, emotional, and behavioral health. A recent federal policy statement highlights this concern and offers guidance about decreasing the use of inappropriate discipline practices and promoting the use of promotion and prevention practices to foster social-emotional competence (U.S. Department of Health and Human Services and U.S. Department of Education, 2014). The provision of a rich universal social-emotional curriculum is essential for young children and provides a foundation for tiered interventions to ensure that all children receive interventions that result in positive social-emotional outcomes. While much work has been done on tiered frameworks in K-12, research on these frameworks is more limited in early care and education settings.

Although the field of early care and education can benefit from knowledge about and lessons learned in K-12 systems of support, there are a number of factors related to young children that should be considered in the design and delivery of tiered supports in early childhood settings. First, preschool-aged children are in the early stages of learning social-emotional competencies. They are learning to express their emotions, get along with their friends, work together, and solve social problems. Given their developmental status, we expect that they will engage in challenging behavior because they often have not learned the skills or competencies for engaging in more appropriate behavior. Thus, we expect young children to have problem behavior and our approaches to supporting social-emotional development should be designed with that in mind. Second, the early childhood context is different than the K-12 system in both location and structure. Young children are served in a variety of settings including public schools, Head Start and a variety of different types of early care and education programs. 
These settings vary in terms of type and amount of funding, qualifications of staff, supports for teachers, the length of the school day; but equally important, these contexts differ in the types and amount of supports and interventions available to promote young children's social competence. These are important considerations when designing supports for young children's social-emotional development.

Designing interventions related to supporting young children's social-emotional development requires not only that we consider effective intervention practices but, that we also consider how to support the implementation of those practices. This is especially important given the range of settings in which young children are served and the qualifications of teachers in those settings. Professional development has been identified as a key competency driver in implementation science frameworks (Halle, Metz, \& Martinez-Beck, 2013). The effectiveness of coaching that includes performance feedback on supporting teachers' implementation of effective practices has been demonstrated in multiple studies (e.g., Hemmeter et al., 2016; Powell, Diamond, Burchinal, \& Koehler, 2010; Snyder et al., 2018; Sutherland et al., 2018). Researchers have demonstrated that when early care and education teachers receive coaching on effective practices, including performance feedback, children receive effective interventions implemented with fidelity, which result in improved social-emotional skills for young children who engage in challenging behavior.

In this volume, we begin to address some of these critical issues. The manuscripts focus on interventions that were designed specifically for supporting young children's social-emotional learning and are being implemented in early childhood settings. They focus not only on the effectiveness of interventions but, also, on the supports that are needed to ensure teachers and other support staff, including coaches, implement the practices with fidelity.

In the first article, Hemmeter, Snyder, and Fox (this issue) examine Pyramid Model research with a focus on examining fidelity, professional development and using a fidelity tool to drive professional development and measure outcomes. They describe the use of a professional development model that includes practice-based coaching (Snyder et al., 2015) (i.e., live coaching or coaching delivered using technology) and teachers' fidelity of implementation. The second article also focuses on teachers' fidelity of implementation. In this study, Sutherland, Conroy, Algina, McLeod, and Wu (this issue) examine two key components of observed treatment integrity (i.e., adherence and competence) and their relation to child outcomes. Next, Downer and his colleagues (this issue) explore the use of data-based decision making and video-based feedback to assist teachers' selection and implementation of behavioral strategies as well as their self-efficacy and child outcomes. Seeley and colleagues (this issue) examine the effects of the First Step to Success Intervention on young children with comorbid externalizing and internalizing behavior problems, including children with elevated anxiety symptoms. Finally, Bierman, Mathias, and Domitrovich (this issue) synthesize the outcomes of the studies presented in this special issue and highlight commonalities, unique contributions, and promising new directions.

Given the number of young children with social, emotional, and behavioral difficulties served in early childhood settings and the availability of research-based intervention programs that can be implemented by teachers with fidelity, we hope this special issue will help the field focus on the application of targeted interventions with fidelity during the early childhood years.

\section{Compliance with Ethical Standards}

Conflict of interest The authors declare that they have no conflict of interest.

Ethical Approval This article does not contain any studies with human participants performed by any of the authors.

\section{References}

Brauner, C. B., \& Stephens, C. B. (2006). Estimating the prevalence of early childhood serious emotional/behavioral disorders: Challenges and recommendations. Public Health Reports, 121(3), 303-310.

Brennan, L. M., Shaw, D. S., Dishion, T. J., \& Wilson, M. (2012). Longitudinal predictors of school-age academic achievement: Unique contributions of toddler-age aggression, oppositionality, inattention, and hyperactivity. Journal of Abnormal Child Psychology, 40, 1289-1300.

Dodge, K. A., Bierman, K. L., Coie, J. D., Greenberg, M. T., Lochman, J. E., McMahon, R. J., et al. (2014). Impact of early intervention on psychopathology, crime, and well-being at age 25 . American Journal of Psychiatry, 172(1), 59-70.

Egger, H. L., \& Angold, A. (2006). Common emotional and behavioral disorders in preschool children: Presentation, nosology, and epidemiology. Journal of Child Psychology and Psychiatry, 47, 313-337.

Gilliam, W. (2005). Prekindergarteners left behind: Expulsion rates in state prekindergarten systems. New Haven, CT: Yale University, Child Study Center.

Halle, T., Metz, A., \& Martinez-Beck, I. (Eds.). (2013). Applying implementation science in early childhood programs and systems. Baltimore, MD: Brookes.

Hemmeter, M. L., Snyder, P., Fox, L., \& Algina, J. (2016). The efficacy of the Pyramid Model: Effects on teachers, classrooms and children. Topics in Early Childhood Special Education, 36, 133-146.

Jones, D. E., Greenberg, M., \& Crowley, M. (2015). Early social-emotional functioning and public health: The relationship between kindergarten social competence and future wellness. American Journal of Public Health, 105, 2283-2290.

Powell, D. R., Diamond, K. E., Burchinal, M. R., \& Koehler, M. J. (2010). Effects of an early literacy professional development intervention on Head Start teachers and children. Journal of Educational Psychology, 102, 299-312. 
Shonkoff, J. P., \& Phillips, D. A. (Eds.). (2000). From neurons to neighborhoods: The science of early childhood development. Washington, DC: National Academies Press.

Snyder, P. A., Hemmeter, M. L., \& Fox, L. (2015). Supporting implementation of evidence-based practices through practice-based coaching. Topics in Early Childhood Special Education, 35, 133-143.

Snyder, P., Hemmeter, M. L., McLean, M., Sandall, S., McLaughlin, T., \& Algina, J. (2018). Effects of professional development on preschool teachers' use of embedded instruction practices. Exceptional Children, 84, 213-232. https://doi.org/10.1177/0014402917 735512 .
Sutherland, K. S., Conroy, M. A., Algina, J., Ladwig, C., Jessee, G., \& Gyure, M. (2018). Reducing child problem behaviors: A randomized controlled trial of BEST in CLASS. Early Childhood Research Quarterly, 42, 31-43.

U.S. Department of Health and Human Services and U.S. Department of Education. (2014). Policy statement on expulsion and suspension policies in early childhood settings. Retrieved from http:// www.acf.hhs.gov/sites/default/files/ecd/expulsion_suspension_ final.pdf. 